\title{
Effectiveness, durability, and safety of darunavir/ ritonavir in HIV-I-infected patients in routine clinical practice in Italy: a postauthorization noninterventional study
}

This article was published in the following Dove Press journal:

Drug Design, Development and Therapy

6 May 2016

Number of times this article has been viewed

\begin{abstract}
Andrea Antinori ${ }^{1}$
Paola Meraviglia ${ }^{2}$

Antonella d'Arminio

Monforte ${ }^{3,4}$

Antonella Castagna ${ }^{5,6}$

Cristina Mussini ${ }^{7}$

Teresa Bini ${ }^{4}$

Nicola Gianotti ${ }^{5}$

Stefano Rusconi ${ }^{8}$

Elisa Colella ${ }^{8}$

Giuseppe Airoldi ${ }^{9}$

Daniela Mancusi ${ }^{10}$

Roberta Termini ${ }^{10}$

'Clinical Department, National Institute for Infectious Diseases

“L. Spallanzani”, Rome, ${ }^{2}$ Department

of Infectious Disease, "L. Sacco"

University Hospital, ${ }^{3}$ Department of

Health Sciences - University of Milan,

${ }^{4}$ Clinic of Infectious Diseases, "San

Paolo" Hospital, ${ }^{5}$ Infectious Diseases,

San Raffaele Scientific Institute,

${ }^{6}$ Università Vita-Salute San Raffaele,

Milan, ${ }^{7}$ Institute of Infectious Diseases,

University of Modena and Reggio

Emilia, Modena, ${ }^{8}$ Infectious Diseases

Unit, DIBIC Luigi Sacco, University

of Milan, ${ }^{9}$ Studio Associato Airoldi,

Cicogna, Ghirri, ${ }^{10} J a n s s e n-C i l a g ~ S p A$,

Medical Affairs, Cologno Monzese,

Milan, Italy
\end{abstract}

Correspondence: Roberta Termini Janssen-Cilag SpA, Medical Affairs, Via Michelangelo Buonarroti 23, 20093 Cologno Monzese, Milan, Italy $\mathrm{Tel}+39022510589$

Fax +39022510499

Email rtermini@its.jnj.com

\begin{abstract}
Current antiretroviral (ARV) therapy for the treatment of human immunodeficiency virus (HIV-1)-infected patients provides long-term control of viral load (VL). Darunavir (DRV) is a nonpeptidomimetic protease inhibitor approved for use with a ritonavir booster (DRV/r). This study evaluated the effectiveness of DRV/r in combination with other ARV agents in routine clinical practice in Italy. In this descriptive observational study, data on utilization of $\mathrm{DRV} / \mathrm{r}$, under the conditions described in the marketing authorization, were collected from June 2009 to December 2012. Effectiveness (VL < 50 copies $/ \mathrm{mL}$ ), tolerability, and durability in four patient groups (two DRV/r-experienced, one ARV-experienced DRV/r-naïve, and one ARV-naïve) were analyzed. Secondary objectives included immunological response, safety, and persistence/discontinuation rates. In total, 875 of 883 enrolled patients were included in the analysis: of these, 662 (75.7\%) completed the follow-up until the end of 2012 and $213(24.3 \%)$ withdrew from the study earlier. Initial DRV dose was $600 \mathrm{mg}$ twice daily $(67.1 \%)$ or $800 \mathrm{mg}$ once daily (32.9\%). Only 16 patients (1.8\%) withdrew from the study due to virological failure. Virological response proportions were higher in patients virologically suppressed at study entry versus patients with baseline VL $\geq 50$ copies/mL in each $A R V$-experienced group, while there was no consistent difference across study groups and baseline VL strata according to baseline $\mathrm{CD} 4^{+}$cell count. $\mathrm{CD} 4{ }^{+}$cell count increased from study entry to last study visit in all the four groups. DRV/r was well tolerated, with few discontinuations due to study-emergent nonfatal adverse events (3.0\% overall, including $2.1 \%$ drug-related) or deaths $(3.0 \%$ overall, all nondrug-related); $35.3 \%$ of patients reported $\geq 1$ adverse events. These observational data show that $\mathrm{DRV} / \mathrm{r}$ was effective and well tolerated in the whole patient population described here. The DRV/r-containing regimen provided viral suppression in a high percentage of patients in all groups, with low rates of discontinuation due to virological failure.
\end{abstract}

Keywords: darunavir/ritonavir, observational, efficacy, durable, safe

\section{Introduction}

Recent advances in highly active antiretroviral (ARV) therapy (ART) regimens for the treatment of human immunodeficiency virus (HIV-1)-infected patients have led to considerable improvements in the long-term control of viral load (VL) and prevention of resistance. Current guidelines recommend the use of a ritonavir-boosted protease inhibitor (PI/r) (alongside other options, including integrase inhibitors) as one of the preferred third agents in addition to a nucleoside reverse transcriptase inhibitor backbone including tenofovir and emtricitabine ${ }^{1-3}$ or abacavir/lamivudine. ${ }^{4,5}$ 
Darunavir (DRV; TMC114) is a second-generation nonpeptidomimetic PI approved for use in combination with a ritonavir booster $(\mathrm{DRV} / \mathrm{r})\left(\right.$ Prezista $\left.^{\circledR}\right)$. DRV/r is used in combination with other ARVs for the treatment of HIV-1 infection in adult patients and can be used in a variety of patients, ranging from those who are treatment-naïve to those who are highly experienced. ${ }^{6-9}$ The efficacy and tolerability of DRV/r have been evaluated in registrative prospective controlled clinical trials in treatment-naïve ${ }^{10,11}$ and treatment-experienced ${ }^{12-15}$ patients with HIV-1 infection, with documented long-term efficacy and tolerability. ${ }^{13,16-18}$ Observational data have shown good long-term persistence with therapy and tolerability of $\mathrm{DRV} / \mathrm{r}$ and support the use of this treatment in combination with a number of ARV agents. ${ }^{19-24}$

The primary objective of this study was to evaluate the effectiveness of DRV/r by collecting data on utilization of this agent (combined with other ARVs) in routine clinical practice in Italy under the conditions described in the marketing authorization. The persistence of DRV/r in terms of both durability of virological response and number of patients remaining on treatment (discontinuation rate) was also evaluated because treatment failure is common in the real-world setting for a number of reasons, including lack of efficacy, loss of virological response, resistance to treatment, adverse reactions, drug adherence, and patient preference. ${ }^{25}$ Furthermore, to investigate whether previous clinical trial data ${ }^{10-18,26-28}$ translate into the setting of routine clinical practice, ${ }^{21-24}$ virological response with DRV/r in previously DRV-treated, ARV-experienced DRV-naïve, and ARV-naïve patients was assessed. Immunovirological responses were analyzed according to VL at study entry. It is well known that a virological response is usually more difficult to achieve in patients with a high VL or a low $\mathrm{CD}^{+}$cell count at baseline. However, a meta-analysis of clinical studies conducted in ARV-experienced patients showed that VL reduction with DRV/r-based ART was independent of baseline VL and CD4 ${ }^{+}$cell count. ${ }^{29}$ This lack of association with baseline VL and $\mathrm{CD}^{+}$has also been documented in a clinical study of DRV/r in treatment-naïve patients ${ }^{11}$ but was not seen in other studies. ${ }^{28,30}$ Therefore, this study also determined the virological response according to $\mathrm{CD}^{+}$cell count at study entry to better assess the impact of this parameter on the virological response in DRV-naïve patients. The safety profile of DRV/r was also analyzed.

\section{Materials and methods Study design and treatment}

This was an observational study in HIV-1-infected patients treated with DRV/r, conducted in the routine clinical setting.
This study was registered on ClinicalTrials.gov with the identifier NCT01375881. Effectiveness, tolerability, and durability data from four groups of patients with HIV-1 infection (two DRV/r-experienced and two DRV/r-naïve) were collected from June 2009 to December 2012. Group 1 included patients who had been on treatment with DRV/r since July 2007 or earlier, and who were part of the DRV/r Early Access Program (EAP) (subjects included in the EAP were heavily experienced, not achieving virological suppression on current regimen, at risk of clinical or immunological progression, and with limited or no treatment options); Group 2 included patients already receiving $\mathrm{DRV} / \mathrm{r}$ in routine clinical practice, with treatment initiated after marketing authorization (July 2007) who had retrospective data from the start of DRV/r treatment available; Group 3 included ARV-experienced DRV-naïve patients; and Group 4 included ARV-naïve DRV-naïve patients.

Patients were treated with DRV/r in routine clinical practice according to the European Summary of Product Characteristics. ${ }^{6}$ In compliance with the "Circolare del Ministero della Salute" dated 02/09/2002 and local guidelines on observational studies dated 20/03/2008, the medicinal product was prescribed according to the current clinical practice and in accordance with the terms of marketing authorization. For the DRV-naïve patients, assignment of a patient to DRV/r was not decided in advance by the study protocol but was selected on an individual basis according to clinical guidelines as part of current clinical practice.

\section{Ethics}

This study was approved by the local ethics committees of all participating centers, as follows:

- National Institute of Infectious Diseases (INMI) "L. Spallanzani” - Rome (Coordinating Center)

- "Umberto I" Policlinic - Rome

- “Luigi Sacco" University Hospital - Milan

_ "San Raffaele" University Hospital - Milan

- "San Paolo" University Hospital - Milan

- "Tor Vergata" Policlinic - Rome

- Hospital "Spedali Civili" - Brescia

- “Cotugno" Hospital - Naples

- "Ospedali Riuniti” - Foggia

- Azienda USL n ${ }^{\circ} 8$ - Presidio Ospedaliero SS. Trinità - Cagliari

- Policlinico Universitario di Cagliari

- University Hospital “Amedeo di Savoia” - Turin

- Università Cattolica del Sacro Cuore - Policlinico Gemelli - Rome

- Ospedale Maggiore - Bologna 
- Hospital "San Giovanni” - Rome

- University Hospital of Modena and Reggio Emilia

- "P. Giaccone" Policlinic - Palermo

- IRCCS Policlinico S. Matteo - Pavia

- Hospital "San Gerardo" - Monza

- Ospedale di Circolo - Busto Arsizio

- Hospital "Galliera" - Genova

- University Hospital "Careggi” - Florence

- A.U.S.L. Pescara - Pescara

- Manzoni Hospital - Lecco

- University Hospital - Ferrara

- Pugliese Ciaccio Hospital - Catanzaro

- Ethics Committee for Clinical Trials of Medicines of the Province of Venice - Venezia

- "S. Orsola" Policlinic - Bologna

- USSL 18 Rovigo - Rovigo

- Varese Hospital - Varese

\section{Participants}

Adult patients ( $\geq 18$ years) with HIV-1 infection who initiated $\mathrm{DRV} / \mathrm{r}$ treatment according to the label (ARV-experienced or ARV-naïve) or started DRV/r as part of an Italian EAP or who were already receiving DRV/r (provided that data at $\mathrm{DRV} / \mathrm{r}$ start were available retrospectively) according to the European Summary of Product Characteristics of DRV were eligible for inclusion in this noninterventional study. All patients provided a signed and dated informed consent form for collection of prospective and retrospective data.

Patients with any of the following criteria were excluded from the study: known hypersensitivity to DRV/r or to any of its excipients; severe hepatic impairment (Child-Pugh class C); coadministration of agents known to interact with $\mathrm{DRV} / \mathrm{r}$; pregnancy or lactation; unable to read, understand, and sign the informed consent form; previously treated with $\mathrm{DRV} / \mathrm{r}$ and discontinued for any reason; and participation in other interventional clinical studies.

\section{Study end points and assessments}

The primary objective was to evaluate the effectiveness of $\mathrm{DRV} / \mathrm{r}$ used under the conditions described in the marketing authorization, in combination with other ARVs, in routine clinical practice in Italy. Effectiveness was primarily measured as virological response (defined as VL $<50$ copies $/ \mathrm{mL}$ ) in a snapshot (last observation carried forward [LOCF]) analysis. Secondary objectives were to evaluate the impact of treatment with DRV/r on immunological response, changes in laboratory parameters, the incidence of treatment-emergent adverse events (AEs), and the rates of persistence in the study or discontinuation for any reason or for specific reasons (notably virological failure).

The VL was measured in each individual center using the more widespread tests commercially available (eg, Abbott RealTime HIV-1 assay) as per manufacturer's instructions.

The $\mathrm{CD}^{+}$cell count was performed in each center as per their clinical practice, using flow cytometry automated systems as per manufacturer's instructions.

Virological outcomes were assessed based on a threshold value for plasma HIV-RNA VL of $<50$ copies/mL (as per protocol, this or a lesser value being the detection limit in all participating centers) and are reported by group, by VL at study entry ( $<50$ or $\geq 50$ copies $/ \mathrm{mL}$ ) within groups, and by baseline $\mathrm{CD}^{+}(<200$ or $\geq 200$ cells $/ \mu \mathrm{L})$ within baseline VL and group. Patients were followed up at $\sim 1,3$, and 6 months and then every 3 months thereafter, in accordance with routine practice.

Blood chemistry variables (liver function tests, glucose, triglycerides, and total cholesterol) were determined at study entry and at intervals of $\sim 6$ months.

\section{Statistical analyses}

Due to the explorative character of this noninterventional study, no specific statistical hypothesis was formulated to calculate sample size when the study was planned. However, a sample of approximately 900 patients was considered adequate to describe the efficacy and safety profile of DRV/r in Italian patients with HIV-1 infection.

Statistical analysis was carried out using the $\mathrm{SAS}^{\circledR}$ system, PC release 9.2 (SAS Institute Inc., Cary, NC, USA).

The baseline of the study was the start of the prospective observation, and follow-up time was, therefore, calculated from this date to the last on-study visit, that is, the end of 2012 or earlier discontinuation. All subjects with HIV-1 infection who received $\geq 1$ dose of $\mathrm{DRV} / \mathrm{r}$ after enrollment were included in the full analysis of demographic and baseline characteristics as well as efficacy and safety data (full analysis population); however, the effective sample size for specific analyses was reduced in some instances because of missing data.

Data are reported for each study group and overall. Continuous data are described using standard descriptive methods, including median and other quartiles $\left(\mathrm{Q}_{1}\right.$ and $\left.\mathrm{Q}_{3}\right)$, mean and standard deviation (SD), and interval estimates, that is, 95\% confidence interval (CI) of the mean. Categorical data are summarized using proportions of totals based on nonmissing values unless otherwise stated; exact 95\% CI values of response proportions were calculated. 
$\mathrm{CD}^{+}$levels were analyzed on a LOCF basis; summary statistics were calculated at enrollment and at last study visit, including mean difference and the associated 95\% CI. To evaluate their impact on changes from baseline to last value, an analysis was performed with baseline $\mathrm{CD}^{+}$levels and time to last observation as covariates within each group.

Blood chemistry variables (transaminases, glucose, triglycerides, and total cholesterol) were summarized at study entry and at intervals of $24 \pm 12$ weeks using data from subjects with complete observations from baseline to $72 \pm 12$ weeks.

LOCF analyses of VL were performed by calculating the proportion of patients with virological response (viral suppression), that is, VL $<50$ copies/mL irrespective of confirmation at the last study visit (snapshot analysis), following two alternative ways to classify study discontinuations:

- Modified intention-to-treat (mITT) analysis: all study discontinuations related to medical events (virological failure, AEs, or death) or due to the patient (consent withdrawal, nonadherence or poor compliance, loss to follow-up) were considered as failures overriding the final VL value, while withdrawals for investigator's decision unrelated to outcome (such as use of nonstandard DRV dose, enrollment in a clinical trial, completion of 12-month treatment of acute infection, or therapy simplification) and $\mathrm{DRV} / \mathrm{r}$ dose modifications were not imputed as failures.

- On-treatment (OT) analysis: only virological failures were considered, study discontinuations for any other reason were not imputed as failures; follow-up was censored at the date of discontinuation.

The analyses of response based on $\mathrm{VL}<50$ copies/mL were stratified by baseline VL, $<50$ or $\geq 50$ copies $/ \mathrm{mL}$, and further (for the LOCF analysis) by baseline CD4+ level, $<200$ or $\geq 200$ cells $/ \mu \mathrm{L}$. Differences in response proportions associated with these characteristics were tested within groups using Fisher's exact test and the CochranMantel-Haenszel chi-square test.

Analyses of virological response based on VL $<50$ copies/mL were also performed at 48 and 96 weeks. Patients who withdrew before the time point ( 48 or 96 weeks) for any medical or patient-related reason, as described earlier, were considered as failures in the mITT analysis, while patients withdrawn for virological failure with the last VL of $\geq 50$ copies $/ \mathrm{mL}$ before the time point were considered as failures in the OT analysis. In either the mITT or the OT analysis, responders were patients still on treatment at the time point with a $\mathrm{VL}<50$ copies/mL, while failures were defined as a $\mathrm{VL} \geq 50$ copies/mL at the time point, using the VL value closest to the time point if available within \pm 90 days, or otherwise imputing its value as $<50$ or $\geq 50$ copies $/ \mathrm{mL}$ if both the last value before this interval and the first value after this interval were consistently so. Patients enrolled after February 2011 were excluded from the analysis at 96 weeks as they could not have reached this time point by the end of the study.

To assess the impact of low (50-399 copies/mL) VL final values on the proportions of primary response defined earlier, a secondary analysis was performed with virological response defined as VL $<400$ copies $/ \mathrm{mL}$ instead of $<50$ copies $/ \mathrm{mL}$.

AEs were summarized descriptively, in particular deaths and AEs that caused study interruption. Proportions and incidence rates were calculated. The probability of a patient withdrawing from the study for specific reasons was calculated over time using Kaplan-Meier curves. Separate curves were produced for each study group representing time since entry in the prospective study.

\section{Results}

\section{Patients}

A total of 883 patients were enrolled in 36 Italian centers between June 5, 2009 and November 30, 2011. Of these, 875 were included in the full analysis set for both effectiveness and safety. Follow-up continued up to the end of 2012 or earlier discontinuation. Flow of patients through the study and number of patients in the analyzed populations and groups are shown in Figure 1. Overall median study duration was 95 weeks $\left(Q_{1}-Q_{3}, 74-121\right.$; mean $\pm \mathrm{SD}, 93 \pm 39$ weeks $)$. Mean study duration was $115 \pm 39,83 \pm 27,91 \pm 50$, and $87 \pm 40$ weeks in Groups 1, 2, 3, and 4, respectively.

Demographic and other characteristics of the study patients at baseline (ie, start of prospective observation) are shown in Table 1. The four groups differed largely in all important anamnestic (time since diagnosis, number of previous drugs), clinical (Centers for Disease Control and Prevention stage), and laboratory (HIV-RNA VL, $\mathrm{CD}^{+}$cell count) characteristics as they were defined as patient groups in different phases of their ARV therapy or DRV course.

The results are reported mainly descriptively by point and interval estimates within groups in the "Virological response" section; stratified analyses assessing the impact of baseline VL and $\mathrm{CD}^{+}$levels within groups have also been reported. Within each of Groups 1, 2, and 3, virological response was higher when baseline $\mathrm{VL}$ was $<50$ copies $/ \mathrm{mL}$ at baseline. Overall response ratios in Groups 3 and 4 (DRVnaïve) were lower than in Groups 1 and 2 (DRV-experienced) 


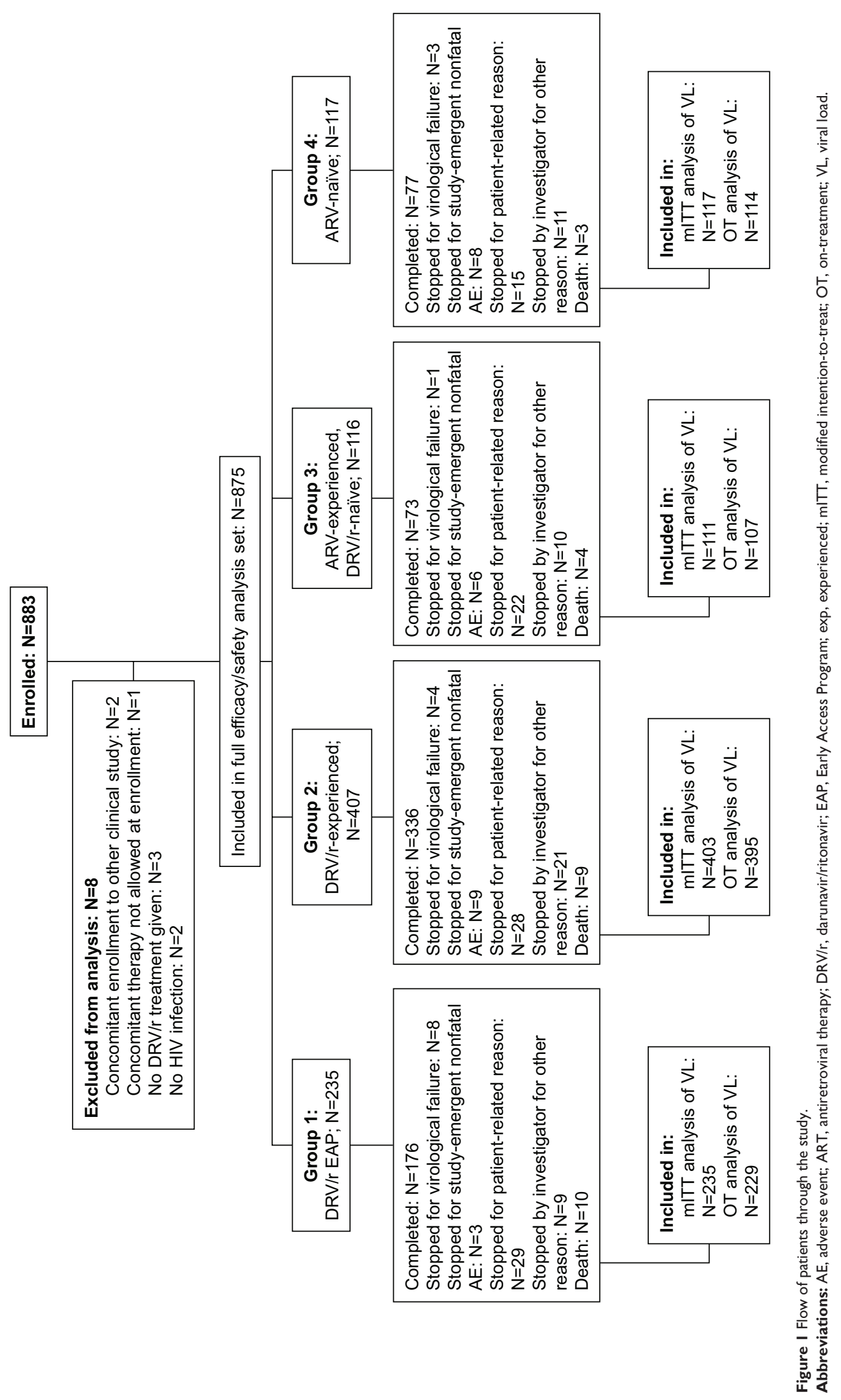


Table I Baseline patient characteristics and demographics (full analysis set)

\begin{tabular}{|c|c|c|c|c|c|}
\hline Patients characteristics & All $(n=875)$ & Group I $(n=235)$ & Group $2(n=407)$ & Group $3(n=116)$ & Group $4(n=1 \mid 7)$ \\
\hline Age (years), mean $\pm S D$ & $46.4 \pm 9.4$ & $49.3 \pm 7.1$ & $46.6 \pm 9.4$ & $44.3 \pm 9.6$ & $42.0 \pm 11.0$ \\
\hline Female, n (\%) & $194(22.2)$ & $46(19.6)$ & $105(25.8)$ & $25(21.6)$ & $18(15.4)$ \\
\hline \multicolumn{6}{|l|}{ HIV-RNA, n (\%) } \\
\hline$<50$ copies $/ \mathrm{mL}$ & $530(62.4)$ & $192(85.0)$ & $299(75.1)$ & $39(35.5)$ & 0 \\
\hline 50-999 copies/mL & $106(12.5)$ & $25(11.1)$ & $61(15.3)$ & $19(17.3)$ & $\mathrm{I}(0.9)$ \\
\hline ।,000-9,999 copies/mL & $43(5.1)$ & $6(2.7)$ & $14(3.5)$ & $19(17.3)$ & $4(3.5)$ \\
\hline 10,000-99,999 copies/mL & $59(6.9)$ & $2(0.9)$ & $6(1.5)$ & $20(18.2)$ & $31(27.0)$ \\
\hline 100,000-999,999 copies $/ \mathrm{mL}$ & $92(10.8)$ & $\mathrm{I}(0.4)$ & $15(3.8)$ & II (10.0) & $65(56.5)$ \\
\hline$\geq 1,000,000$ copies $/ \mathrm{mL}$ & $19(2.2)$ & 0 & $3(0.8)$ & $2(1.8)$ & $14(12.2)$ \\
\hline NA & 26 & 9 & 9 & 6 & 2 \\
\hline \multicolumn{6}{|l|}{$\mathrm{CD}^{+}, \mathrm{n}(\%)$} \\
\hline$<100$ cells $/ \mu \mathrm{L}$ & $100(11.7)$ & $7(2.7)$ & $25(6.2)$ & $13(11.7)$ & $56(47.9)$ \\
\hline $100-199$ cells $/ \mu \mathrm{L}$ & $91(10.6)$ & $20(8.8)$ & $45(11.2)$ & $12(10.8)$ & $14(12.0)$ \\
\hline 200-349 cells/ $/ \mathrm{L}$ & $199(23.2)$ & $52(23.0)$ & $89(22.1)$ & $34(30.6)$ & $24(20.5)$ \\
\hline 350-499 cells/uL & $211(24.6)$ & $64(28.3)$ & $101(25.1)$ & $28(25.2)$ & $18(15.4)$ \\
\hline$\geq 500$ cells $/ \mu \mathrm{L}$ & $255(29.8)$ & $84(37.2)$ & $142(35.3)$ & $24(21.6)$ & $5(4.3)$ \\
\hline NA & 19 & 9 & 5 & 5 & 0 \\
\hline \multicolumn{6}{|l|}{ Time since HIV diagnosis, $\mathrm{n}(\%)$} \\
\hline $0-1$ year & $146(17.1)$ & 0 & $53(13.4)$ & $7(6.4)$ & $86(73.5)$ \\
\hline$>1-10$ years & $146(17.1)$ & $6(2.6)$ & $81(20.5)$ & $34(30.9)$ & $25(21.4)$ \\
\hline$>10-15$ years & $154(18.0)$ & $62(26.6)$ & $67(16.9)$ & $22(20.0)$ & $3(2.6)$ \\
\hline$>15-20$ years & $192(22.4)$ & $89(38.2)$ & $85(21.5)$ & $17(15.5)$ & $\mathrm{I}(0.9)$ \\
\hline$>20$ years & $218(25.5)$ & $76(32.6)$ & $110(27.8)$ & $30(27.3)$ & $2(1.7)$ \\
\hline NA & 19 & 2 & 11 & 6 & 0 \\
\hline \multicolumn{6}{|l|}{ CDC clinical stage, $n(\%)$} \\
\hline$A$ & $258(29.5)$ & $29(12.3)$ & $138(33.9)$ & $36(31.0)$ & $55(47.0)$ \\
\hline B & $261(29.8)$ & $80(34.0)$ & $118(29.0)$ & $39(33.6)$ & $24(20.5)$ \\
\hline C & $356(40.7)$ & $126(53.6)$ & $151(37.1)$ & $4 \mathrm{I}(35.3)$ & $38(32.5)$ \\
\hline $\begin{array}{l}\text { Time from first DRV dose to } \\
\text { study entry (days), mean } \pm \text { SD }\end{array}$ & - & $1,256 \pm 224$ & $494 \pm 382$ & 0 & 0 \\
\hline \multicolumn{6}{|c|}{ Number of other ARV drugs before study start, $\mathrm{n}(\%)$} \\
\hline 0 & $117(13.7)$ & 0 & 0 & 0 & 117 \\
\hline $1-3$ & $120(14.0)$ & I (0.4) & 89 (22.9) & $30(25.9)$ & \\
\hline 4-6 & $102(11.8)$ & $6(2.6)$ & $73(18.8)$ & $23(19.8)$ & \\
\hline $7-9$ & $167(19.5)$ & $29(12.3)$ & $101(26.0)$ & 37 (31.9) & \\
\hline $10-12$ & $167(19.5)$ & $68(28.9)$ & 77 (19.8) & $22(19.0)$ & \\
\hline $13-15$ & $115(13.4)$ & $76(32.3)$ & $36(9.3)$ & $3(2.6)$ & \\
\hline $16-22$ & $69(8.1)$ & $55(23.4)$ & $13(3.3)$ & I (0.9) & \\
\hline NA & 18 & 0 & 18 & 0 & \\
\hline
\end{tabular}

Notes: Group I, patients who were part of the DRV/r Early Access Program (EAP); Group 2, patients already receiving DRV/r in routine clinical practice; Group 3, ARVexperienced DRV-naive patients; Group 4, ARV-naive patients.

Abbreviations: ARV, antiretroviral; CDC, Centers for Disease Control and Prevention; DRV/r, darunavir boosted with ritonavir; HIV, human immunodeficiency virus; NA, not available; SD, standard deviation.

reflecting the fact that most Group 3 patients and all Group 4 patients had high baseline VL, while most DRV-experienced patients had a baseline VL $<50$ copies/mL. Groups 1 and 2 were similar in the proportion of patients with baseline $\mathrm{VL}<50$ copies/mL and in the response ratios within baseline VL stratum. Response ratios in Group 4 patients with baseline $\mathrm{VL} \geq 50$ copies/mL were higher than in Group 3 patients with baseline VL $\geq 50$ copies $/ \mathrm{mL}$.

A high percentage of patients in Groups 1-3 had a long duration of HIV infection. The mean interval from DRV start to entry in the study was 41 months for patients in Group 1 and 16 months for patients in Group 2 (Table 1). At DRV start, all Group 1 patients (ex-EAP) were ARV-experienced, while of Group 2 patients, 294 were ARV-experienced, 50 ARV-naïve, and 63 unknown.

The median number of ARV active principles (other than $\mathrm{DRV} / \mathrm{r}$ ) reported before study start was thirteen in Group 1, eight in Group 2, and seven in Group 3. Overall, 61\% of the patients received two other active ARV drugs ongoing at study start; tenofovir + emtricitabine were given together to $55.5 \%$ of the patients (91.5\% of ARV-naïve), including $11.9 \%$ with additional raltegravir (Table 2 ). Patients initially 
Table 2 Concomitant ARV treatments and DRV/r dose during the study

\begin{tabular}{|c|c|c|c|c|c|}
\hline Concomitant ARV Drugs & All $(n=875)$ & Group I (n=235) & Group $2(n=407)$ & Group $3(n=116)$ & Group $4(n=1 \mid 7)$ \\
\hline \multicolumn{6}{|c|}{ Number of other ARV drugs at study start, n (\%) } \\
\hline None reported & $10(1.1)$ & $5(2.1)$ & $3(0.7)$ & $2(1.7)$ & 0 \\
\hline I & $130(14.9)$ & $34(14.5)$ & $73(17.9)$ & $18(15.5)$ & $5(4.3)$ \\
\hline 2 & $534(6 \mid .0)$ & II 5 (48.9) & $239(58.7)$ & $78(67.2)$ & $102(87.2)$ \\
\hline 3 & $168(19.2)$ & $68(28.9)$ & $74(18.2)$ & $16(13.8)$ & $10(8.5)$ \\
\hline 4 & $33(3.8)$ & $13(5.5)$ & $18(4.5)$ & $2(1.7)$ & 0 \\
\hline \multicolumn{6}{|l|}{ Other ARV drugs at study start, n (\%) } \\
\hline Tenofovir & $542(61.9)$ & $124(52.8)$ & $238(58.5)$ & $73(62.9)$ & $107(91.5)$ \\
\hline Emtricitabine & $493(56.3)$ & $100(42.6)$ & $220(54.1)$ & $66(56.9)$ & 107 (9I.5) \\
\hline Raltegravir & $336(38.4)$ & $119(50.6)$ & $167(40.0)$ & $42(36.2)$ & $8(6.8)$ \\
\hline Lamivudine & 164 (I8.7) & $60(25.5)$ & $80(21.0)$ & $19(16.4)$ & $5(4.3)$ \\
\hline Etravirine & $86(9.8)$ & 35 (19.6) & 45 (II.I) & $6(5.2)$ & 0 \\
\hline Abacavir & $61(7.0)$ & $18(4.9)$ & $28(6.9)$ & $10(8.6)$ & $5(4.3)$ \\
\hline Maraviroc & $52(5.9)$ & $13(5.5)$ & 31 (7.6) & $8(6.9)$ & 0 \\
\hline Zidovudine & $40(4.6)$ & $20(8.5)$ & $19(4.7)$ & 0 & I (0.9) \\
\hline Didanosine & $22(2.5)$ & $14(6.0)$ & $6(1.5)$ & $2(1.7)$ & 0 \\
\hline Enfuvirtide & $14(1.6)$ & $6(2.6)$ & $3(0.7)$ & $2(1.7)$ & $3(2.6)$ \\
\hline Efavirenz & $10(1.1)$ & $6(2.6)$ & $4(1.0)$ & 0 & 0 \\
\hline Atazanavir & $7(0.8)$ & $4(1.7)$ & 0 & 0 & $3(2.6)$ \\
\hline Stavudine & $5(0.6)$ & 0 & $4(1.0)$ & I (0.8) & 0 \\
\hline Nevirapine & $5(0.6)$ & $2(0.9)$ & $2(0.5)$ & I $(0.8)$ & 0 \\
\hline Lopinavir & I $(0.1)$ & 0 & I $(0.2)$ & 0 & 0 \\
\hline \multicolumn{6}{|l|}{ Frequent $A R V$ associations at study start, $n$ (\%) } \\
\hline Tenofovir + Emtricitabine & $486(55.5)$ & $95(40.4)$ & $218(53.6)$ & $66(56.9)$ & $107(9 \mid .5)$ \\
\hline Abacavir + Lamivudine & $55(6.3)$ & $16(6.8)$ & $26(6.4)$ & $8(6.9)$ & $5(4.3)$ \\
\hline Zidovudine + Lamivudine & $31(3.5)$ & $16(6.8)$ & $15(3.7)$ & 0 & 0 \\
\hline Raltegravir + Lamivudine & $65(7.4)$ & $22(9.4)$ & $37(9.1)$ & $6(5.2)$ & 0 \\
\hline Raltegravir + Etravirine & $43(4.9)$ & $21(8.9)$ & $17(4.2)$ & $5(4.3)$ & 0 \\
\hline Tenofovir + Emtricitabine + Raltegravir & $104(11.9)$ & $37(15.7)$ & $53(13.0)$ & II (9.5) & $3(2.6)$ \\
\hline \multicolumn{6}{|l|}{ DRV dose at study start, n (\%) } \\
\hline $600 \mathrm{mg}$ bid & $587(67.1)$ & $232(98.7)$ & $262(64.4)$ & $81(69.8)$ & $12(10.3)$ \\
\hline $800 \mathrm{mg}$ qd & $288(32.9)$ & $3(1.3)$ & $145(35.6)$ & $35(30.2)$ & $105(89.7)$ \\
\hline \multicolumn{6}{|c|}{ DRV dose changes after study start, $\mathrm{n}(\%)$} \\
\hline $600 \mathrm{mg}$ bid to $800 \mathrm{mg}$ qd & $30(3.4)$ & $15(6.4)$ & $8(2.0)$ & $2(1.7)$ & $5(4.3)$ \\
\hline $800 \mathrm{mg}$ qd to $600 \mathrm{mg}$ bid & $4(0.5)$ & 0 & $2(0.5)$ & $\mathrm{I}(0.9)$ & $\mathrm{I}(0.9)$ \\
\hline
\end{tabular}

Notes: Group I, patients who were part of the DRV/r Early Access Program (EAP); Group 2, patients already receiving DRV/r in routine clinical practice; Group 3, ARVexperienced DRV-naïve patients; Group 4, ARV-naïve patients.

Abbreviations: ARV, antiretroviral; DRV/r, darunavir boosted with ritonavir $800 / 100$ or $600 / 100 \mathrm{mg}$; bid, twice daily; qd, once daily.

received DRV/r 600/100 mg twice daily (bid) or 800/100 mg once daily (qd) according to their clinical conditions and current approved dose (Table 2). The majority of patients (96.1\%) remained on their initial dosage throughout the study (Table 2): 557 (94.9\% of 587) on 600/100 mg bid and 284 (98.6\% of 288 ) on $800 / 100 \mathrm{mg}$ qd. Of the 34 patients (3.9\%) who changed their DRV/r dose after study entry, 30 (5.1\% of 587) changed from $600 / 100 \mathrm{mg}$ bid to $800 / 100 \mathrm{mg}$ qd during the study and four ( $1.4 \%$ of 288 ) changed from $800 / 100 \mathrm{mg} \mathrm{qd}$ to $600 / 100 \mathrm{mg}$ bid.

\section{Virological response}

Virological response proportions at the last study visit in the mITT analysis (ie, with medical and patient-related discontinuations imputed as failures) and in the OT analysis (ie, based on last VL only with no imputation), with virological failure set to $\mathrm{VL} \geq 50$ copies $/ \mathrm{mL}$ as prespecified, are shown in Table 3. When assessed according to baseline VL in ARVexperienced patients (Groups 1, 2, and 3), virological response was higher in patients with baseline VL $<50$ copies $/ \mathrm{mL}$ versus those with baseline $\mathrm{VL} \geq 50$ copies $/ \mathrm{mL}(P<0.01$ within each group; Table 3). Within the same baseline VL stratum of $<50$ or $\geq 50$ copies $/ \mathrm{mL}$, there was no consistent difference across study groups between patients with baseline $\mathrm{CD}^{+} \geq 200$ cells $/ \mu \mathrm{L}$ and $\mathrm{CD}^{+}<200$ cells $/ \mu \mathrm{L}$, in either the OT or the mITT analyses $(P \geq 0.10$ within each group controlling for baseline VL class and within each CD4 ${ }^{+}$ cell count; Table 3). 


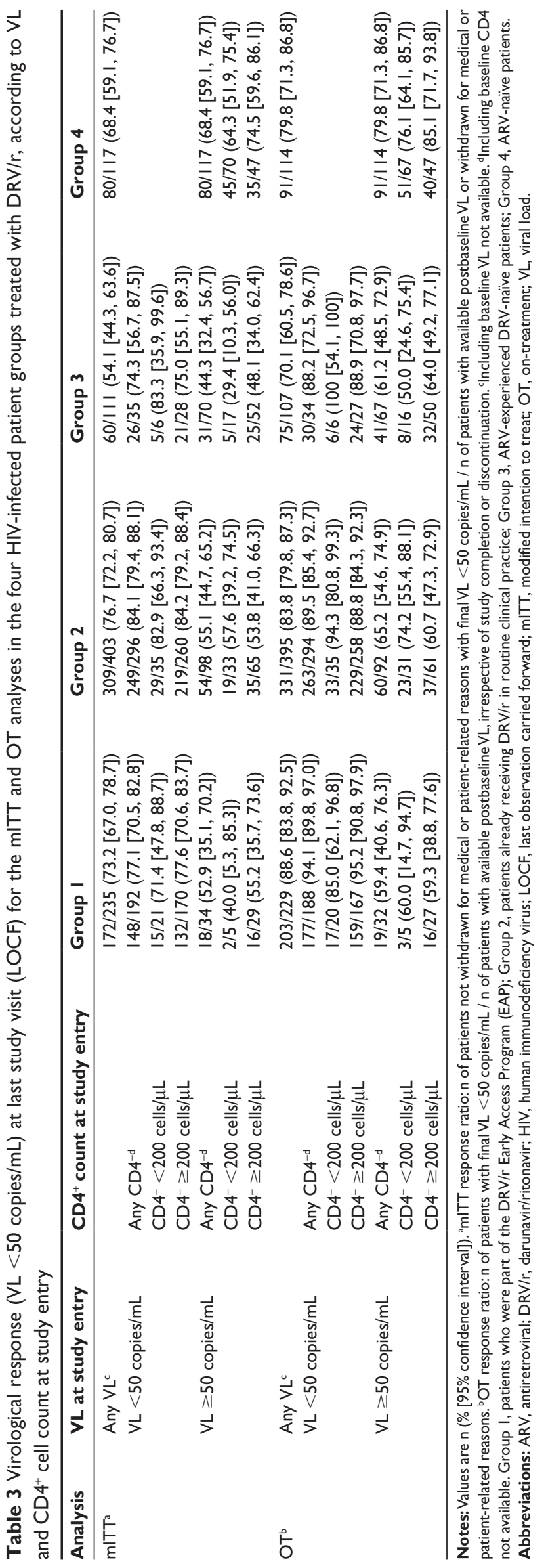

Virological response proportions at 48 weeks and 96 weeks by mITT and OT, with virological failure set to $\mathrm{VL} \geq 50$ copies $/ \mathrm{mL}$, are reported in Table 4 . As in the LOCF analysis, virological response within each ARV-experienced group was higher in subjects with baseline $\mathrm{VL}<50$ copies $/ \mathrm{mL}$ than in those with baseline $\mathrm{VL} \geq 50$ copies $/ \mathrm{mL}$, although not all differences achieved statistical significance $(P<0.0001$ for all Group 1 analyses; $P<0.0001$ for the analyses in Group 2, except $P=0.15$ by OT at 96 weeks; $P=0.07$ by mITT at 48 weeks, $P=0.15$ by OT at 48 weeks, $P=0.04$ by mITT at 96 weeks, and $P=0.46$ by OT at 96 weeks in Group 3). Response by mITT decreased from 48 to 96 weeks in all groups, while OT response proportions at 96 weeks compared to 48 weeks decreased in the ex-EAP patients, increased in the ARV-naïve patients, and was approximately constant in the other two groups.

In secondary analyses with virological failure defined as $\mathrm{VL} \geq 400$ copies $/ \mathrm{mL}$ instead of $\geq 50$ copies $/ \mathrm{mL}$, overall response proportions by mITT were $181 / 235(77.0 \%)$ in Group 1, 340/403 (84.4\%) in Group 2, 72/111 (64.9\%) in Group 3, and 86/115 (74.8\%) in Group 4, and 218/229 (95.2\%), 372/395 (94.2\%), 91/107 (85.0\%), and 106/112 (94.6\%), respectively, by OT. Comparison with these proportions shows that in the primary OT analysis, most virological failures in Groups 1, 2, and 4 and half in Group 3 were due to final VL values between 50 and 399 copies $/ \mathrm{mL}$.

Only 16 withdrawals due to virological failures occurred:

- eight in patients from the EAP study (Group 1): all except one harbored multiple mutations, including DRV resistance associated mutations (RAMs), at study entry;

- four in other DRV-experienced patients (Group 2): three had only a resistance test at study entry, one of which had both reverse transcriptase (RT) and DRV RAMs; only one patient had a test both at study entry (only RT mutations) and at study end (no DRV RAMs);

- one in an ARV-experienced DRV-naïve patient (Group 3): resistance test was available only at baseline showing multiple PI mutations;

- three in ARV-naïve patients (Group 4): one patient had both study entry and follow-up resistance test with no mutations at both time points; one patient had only final resistance test with only RT mutation and no PI mutations; one patient had only study start resistance test with no mutations.

\section{Follow-up and treatment persistence}

Crude ratios of persistence in the study at the last available observation were $74.9 \%$ in Group 1, 82.6\% in Group 2, 


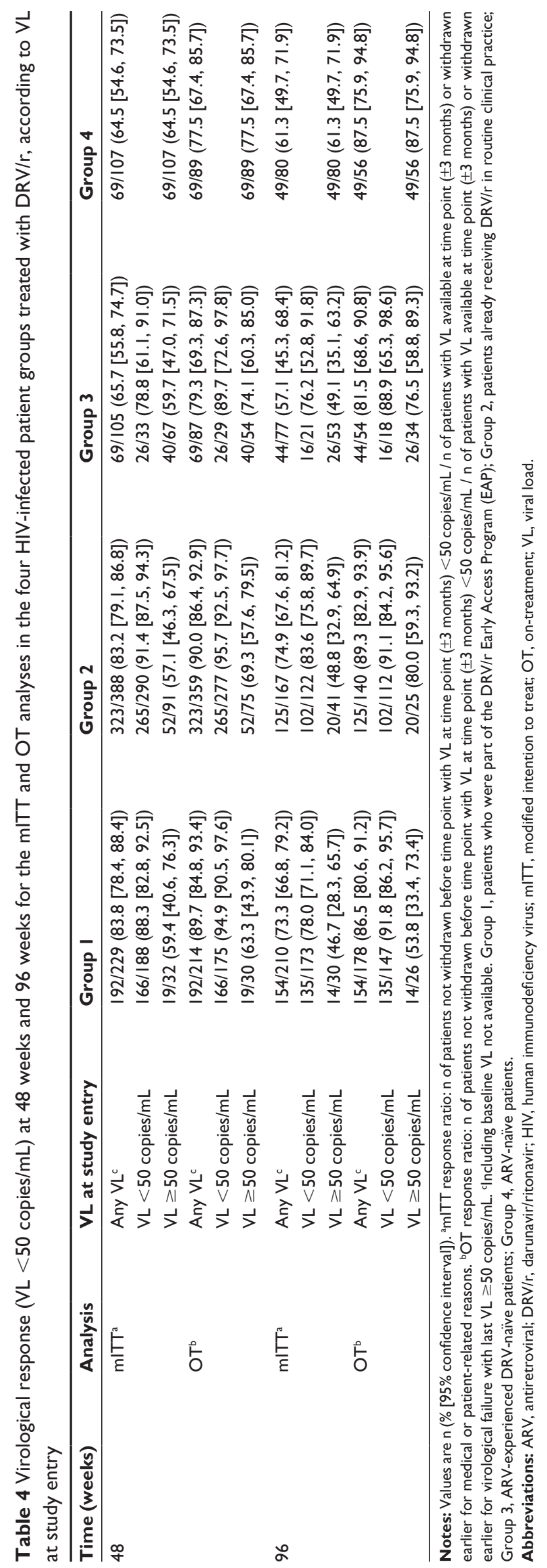

$62.9 \%$ in Group 3, and 65.8\% in Group 4. Reasons for study discontinuation in the four groups are shown in Table 5. In total, 213 patients $(24.3 \%)$ discontinued treatment, but virological failure was the reason in only 16 patients $(1.8 \%)$; $7.3 \%$ were lost to follow-up, $2.9 \%$ discontinued due to lack of compliance (including one patient who withdrew consent), $3.0 \%$ dropped out due to the onset of study-related nonfatal AEs, and $0.6 \%$ discontinued for other patient-related reasons. Other study discontinuations (5.8\%) occurred because of investigators' decisions based on conditions present at study entry or for other reasons unrelated to outcome (eg, use of a nonstandard DRV dose, enrollment in a clinical trial, completion of 12-months' treatment for acute infection, or therapy simplification). Overall, 26 patients $(3.0 \%)$ died during the study; none of the deaths were considered to be related to DRV/r.

Kaplan-Meier curves showing, for each study group, the cumulative probabilities of continuing in the study or discontinuing for various reasons are presented in Figures 2-5. Persistence rates ( $100 \%$ minus the probability of discontinuing for any reason) from the start of prospective observation up to 48 weeks (or exactly 1 year) were $90.2 \%$ (89.0\%) in Group 1 , 90.2\% (89.4\%) in Group 2, 76.8\% (76.0\%) in Group 3, $77.9 \%(76.2 \%)$ in Group 4, and 86.8\% (85.8\%) overall. Corresponding values from the start of prospective observation up to 96 weeks (or exactly 2 years) were $79.8 \%$ (79.3\%), $81.1 \%$ (80.6\%), 67.4\% (66.1\%), 65.9\% (64.7\%), and 76.7\% (76.0\%). The Kaplan-Meier probability of withdrawal due to virological failure at 96 weeks (and identically at 2 years) from study start was $2.3 \%$ in Group $1,1.1 \%$ in Group 2, 1.4\% in Group 3, 3.5\% in Group 4, and 1.8\% overall, similar to the crude proportion of discontinuations for this reason at the last available observation (Figures 2-5).

\section{Immunological recovery}

The mean baseline $\mathrm{CD}^{+}$cell counts varied between the four groups, being considerably higher in DRV-experienced patients compared with DRV-naïve patients, especially if ARV-naïve (Table 6). CD4+ cell counts increased from baseline to last study visit in all four groups (Table 6$)$ : mean ( $95 \%$ CI) increases were 54 cells $/ \mu \mathrm{L}(32,76)$ in ex-EAP patients, 59 cells $/ \mu \mathrm{L}(44,74)$ in other DRV-experienced patients, 138 cells $/ \mu \mathrm{L}(100,176)$ in ARV-experienced DRV-naïve patients, and 266 cells $/ \mu \mathrm{L}(232,300)$ in ARV-naïve patients. The analysis of covariance showed that in all groups, the increase from baseline to last value was significantly greater for longer durations of observation $(P<0.0001)$, although the relationship was not necessarily linear, and in patients with lower baseline values $(P<0.05)$. 
Table 5 Reasons for discontinuation from the study

\begin{tabular}{|c|c|c|c|c|c|}
\hline Reason for discontinuation, $\mathrm{n}(\%)$ & All $(n=875)$ & Group I $(n=235)$ & Group $2(n=407)$ & Group $3(n=\mid 16)$ & Group $4(n=\mid 17)$ \\
\hline$\overline{T \text { Total }}$ & $213(24.3)$ & $59(25.1)$ & $71(17.4)$ & $43(37.1)$ & $40(34.2)$ \\
\hline Insufficient virological response & $16(1.8)$ & $8(3.4)$ & $4(1.0)$ & I (0.9) & $3(2.6)$ \\
\hline Never suppressed during the study & 11 & 5 & 3 & I & 2 \\
\hline Rebound & 5 & 3 & I & 0 & 1 \\
\hline Death $^{\mathrm{a}}$ & $26(3.0)$ & $10(4.3)$ & $9(2.2)$ & $4(3.4)$ & $3(2.6)$ \\
\hline Neoplastic disease & 10 & 4 & 3 & I & 1 \\
\hline Infection & 4 & 0 & 3 & 2 & 0 \\
\hline Vascular accident & 3 & 2 & I & 0 & 0 \\
\hline Hepatic failure or hepatitis & 2 & 0 & I & I & 0 \\
\hline Bone fracture & I & I & 0 & 0 & 0 \\
\hline Car accident & 2 & I & 0 & 0 & I \\
\hline Suicide & I & 0 & 0 & 0 & 1 \\
\hline Sudden death & I & 0 & I & 0 & 0 \\
\hline Unknown cause & 2 & 2 & 0 & 0 & 0 \\
\hline$A E$ emerging during the study & $26(3.0)$ & $3(1.3)$ & $9(2.2)$ & $6(5.2)$ & $8(6.8)$ \\
\hline Neoplastic disease worsening & 3 & 0 & 2 & $\mathrm{I}^{\mathrm{b}}$ & 0 \\
\hline Gastrointestinal disorders $\mathrm{s}^{\mathrm{a}}$ & 2 & 0 & I & I & 0 \\
\hline Encephalopathy ${ }^{\mathrm{a}}$ & I & 0 & 0 & 0 & I \\
\hline Myocarditis-pleurisy ${ }^{a}$ & I & 0 & 0 & I & 0 \\
\hline Acute renal failure ${ }^{\mathrm{a}}$ & I & 0 & I & 0 & 0 \\
\hline Rash & 4 & 0 & 0 & I & 3 \\
\hline Diarrhea & 5 & I & 2 & I & I \\
\hline Hyperlipidemia & 3 & 0 & 2 & I & 0 \\
\hline Hyperlipidemia-diabetes & I & I & 0 & 0 & 0 \\
\hline Hepatic enzymes increased & 2 & 0 & 0 & 0 & 2 \\
\hline Gastrointestinal disorder unspecified & I & 0 & I & 0 & 0 \\
\hline Coronary artery disorder & I & I & 0 & 0 & 0 \\
\hline Lipodystrophy & I & 0 & 0 & 0 & 1 \\
\hline Other patient-related reason & $5(0.6)$ & $\mathrm{I}(0.4)$ & $3(0.7)$ & 0 & $\mathrm{I}(0.9)$ \\
\hline Pregnancy & I & 0 & I & 0 & 0 \\
\hline Concern for potential male infertility & I & 0 & 0 & 0 & 1 \\
\hline Unspecified (patient's choice) & 3 & I & 2 & 0 & 0 \\
\hline Lack of compliance & $25(2.9)$ & $4(1.7)$ & $8(2.0)$ & $7(6.0)$ & $6(5.1)$ \\
\hline Loss to follow-up & $64(7.3)$ & $24(10.2)$ & $17(4.2)$ & $15(12.9)$ & $8(6.8)$ \\
\hline Late decision for conditions present at entry & $14(1.6)$ & $3(1.3)$ & $3(0.7)$ & $7(6.0)$ & $\mathrm{I}(0.9)$ \\
\hline Investigator's decision for other reasons & $37(4.2)$ & $6(2.6)$ & $18(4.4)$ & $3(2.6)$ & $10(8.5)$ \\
\hline
\end{tabular}

Notes: a Unrelated to darunavir according to investigator. 'D Died 7 days after study discontinuation. Group I, patients who were part of the DRV/r Early Access Program (EAP); Group 2, patients already receiving DRV/r in routine clinical practice; Group 3, ARV-experienced DRV-naïve patients; Group 4, ARV-naïve patients.

Abbreviations: $A E$, adverse event; $A R V$, antiretroviral; $D R V / r$, darunavir/ritonavir.

\section{Tolerability}

Safety data from 875 patients were analyzed. DRV/r-based treatment was well tolerated, with $35.3 \%$ of patients reporting $\geq 1$ AE. Treatment discontinuations due to AEs were few ( $n=26,3.0 \%$ overall): for 18 of these, a relationship with DRV/r treatment was not excluded by the investigator (Table 5). The most frequent AEs that led to treatment discontinuation were diarrhea $(\mathrm{n}=5)$ and $\operatorname{rash}(\mathrm{n}=4)$ (Table 5).

Median and other quartiles of serum biochemistry values for each group are reported in Table 7, only for patients with a complete set of observations at each time point: baseline (within 3 months before enrollment), 24 $\pm 12,48 \pm 12$, and
$72 \pm 12$ weeks. Levels of the liver enzymes alanine aminotransferase and aspartate aminotransferase remained stable from study entry through 72 weeks in DRV-experienced patients, decreased slightly in ARV-experienced DRVnaïve patients, and decreased more markedly in ARV-naïve patients. Blood glucose concentrations remained stable in all groups from study entry through 72 weeks. Serum triglyceride levels decreased slightly in ex-EAP patients, remained relatively stable in Groups 2 and 3, and increased in ARVnaïve patients up to 48 weeks. Total cholesterol levels were essentially unchanged from study entry through 72 weeks in both DRV-experienced groups, while in ARV-experienced DRV-naïve patients and especially in ARV-naïve patients, 


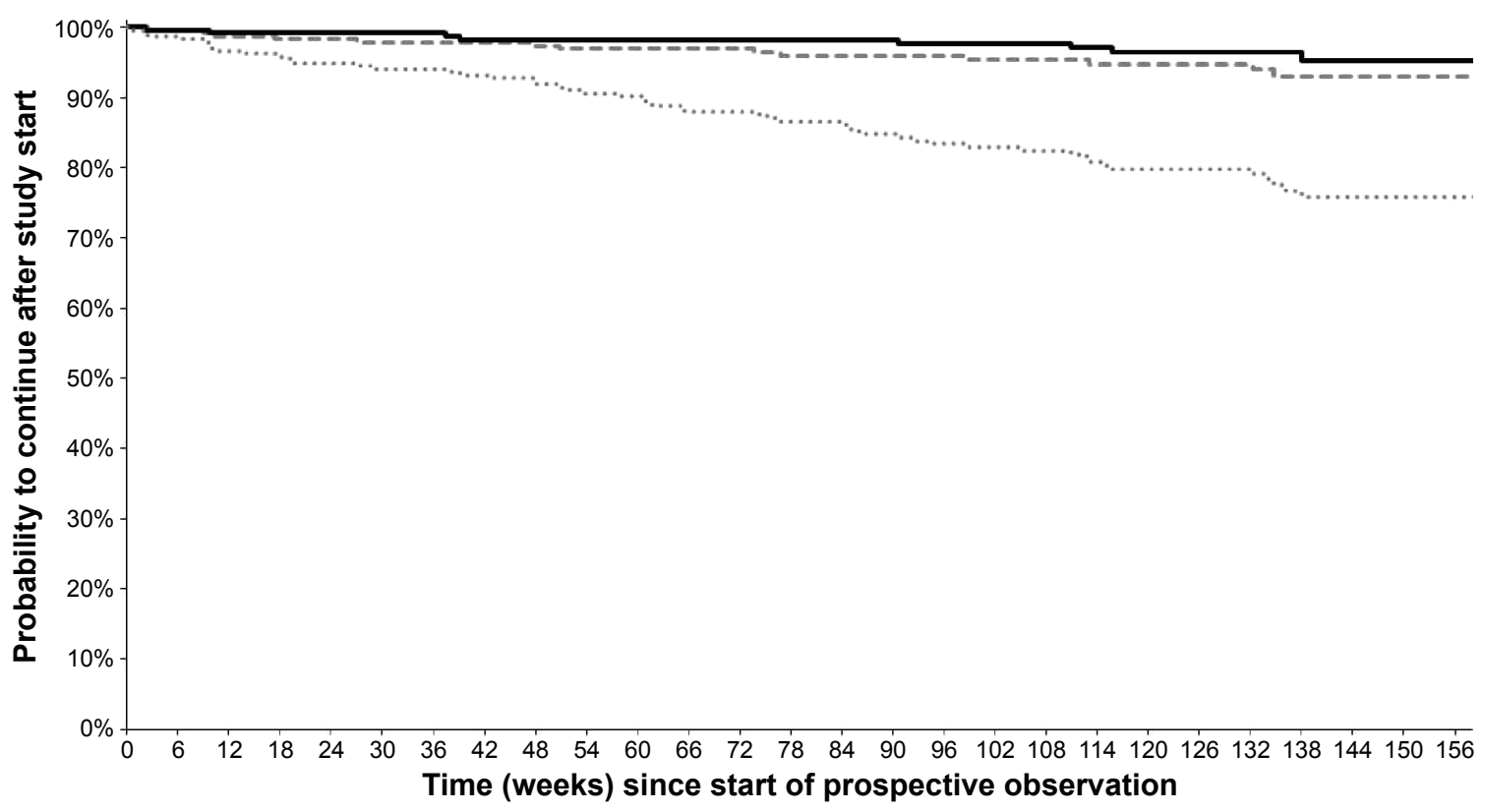

- . Discontinuation for AE, including death

Withdrawal for virologic failure

- Medical or patient-related discontinuation

Figure 2 Kaplan-Meier curves from start of prospective observation showing study discontinuation by reason of interruption in Group I ( $\mathrm{n}=235$ ) - patients who were part of the DRV/r Early Access Program (EAP).

Abbreviations: $A E$, adverse event; DRV/r, darunavir/ritonavir.

median values increased at 24 weeks after which they did not increase further.

\section{Discussion}

Although randomized, controlled clinical studies provide the highest level of evidence in terms of efficacy and tolerability for a specific treatment, observational studies are important to help clinical trial data be translated into the real-world setting because they provide information about persistence and durability in routine clinical practice that are not possible to obtain from clinical studies. Moreover, observational studies enroll an unselected population and allow long-term observation of

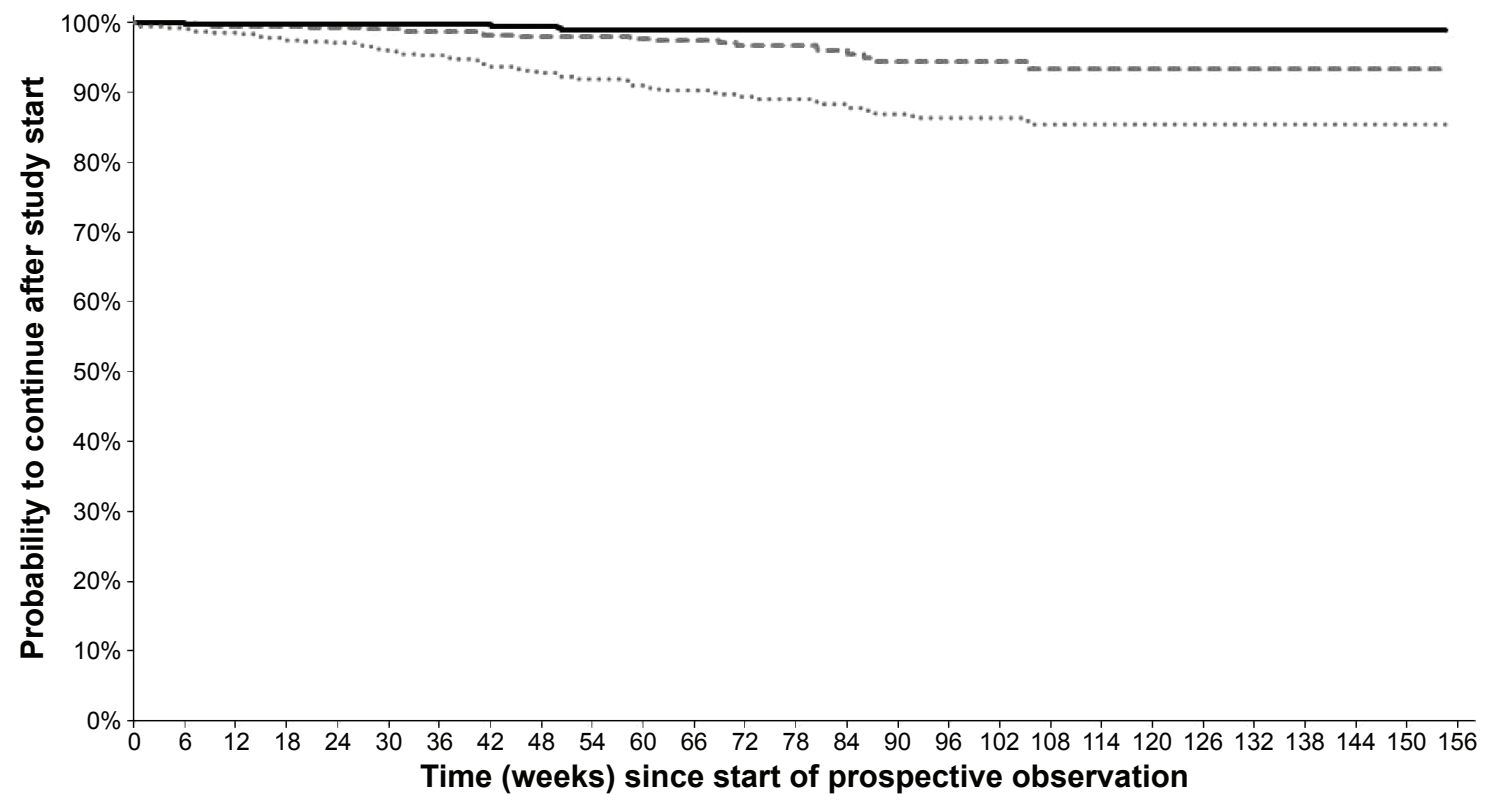

- - Discontinuation for AE, including death —Withdrawal for virologic failure ..... Medical or patient-related discontinuation

Figure 3 Kaplan-Meier curves from start of prospective observation showing study discontinuation by reason of interruption in Group 2 ( $\mathrm{n}=407$ ) - patients already receiving $D R V / r$ in routine clinical practice.

Abbreviations: $A E$, adverse event; DRV/r, darunavir/ritonavir. 


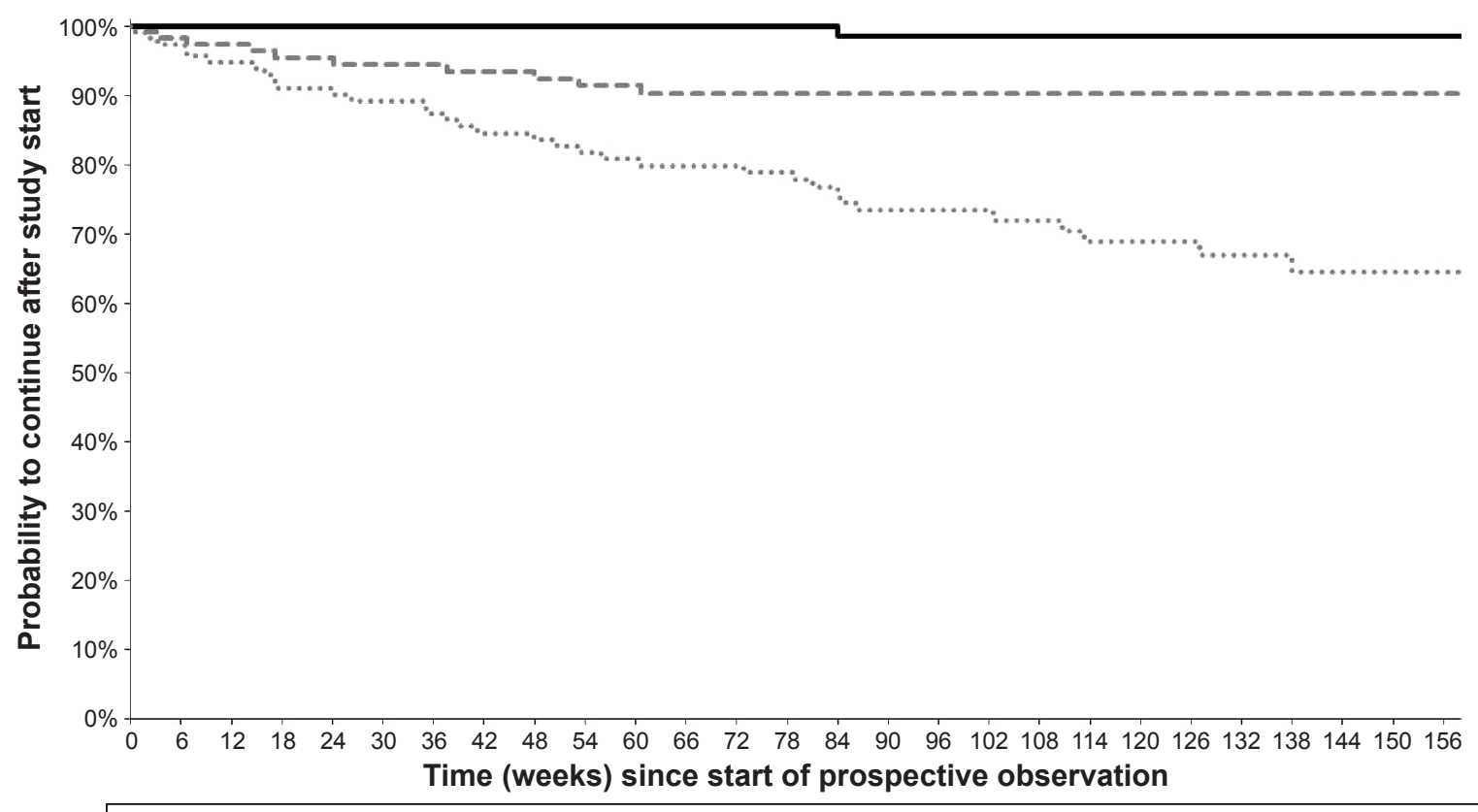

- - - Discontinuation for AE, including death W Withdrawal for virologic failure ..... Medical or patient-related discontinuation

Figure 4 Kaplan-Meier curves from start of prospective observation showing study discontinuation by reason of interruption in Group 3 ( $n=I$ I6) - ARV-experienced DRV-naïve patients.

Abbreviations: ARV, antiretroviral; AE, adverse event; DRV, darunavir.

effectiveness and safety of drug combinations. This analysis of real-world data of DRV/r treatment is the first one to include the range of patients likely to be seen in clinical practice.

The results showed that most patients, regardless of previous clinical and treatment history, were treated with a stable dose of DRV/r of $600 / 100 \mathrm{mg}$ bid or $800 / 100 \mathrm{mg} \mathrm{qd}$ and remained on study for a mean of $93 \pm 39$ weeks. High persistence rates were seen in all groups, especially in both DRV-experienced groups, with an overall persistence rate of $>75 \%$ after 24 months.

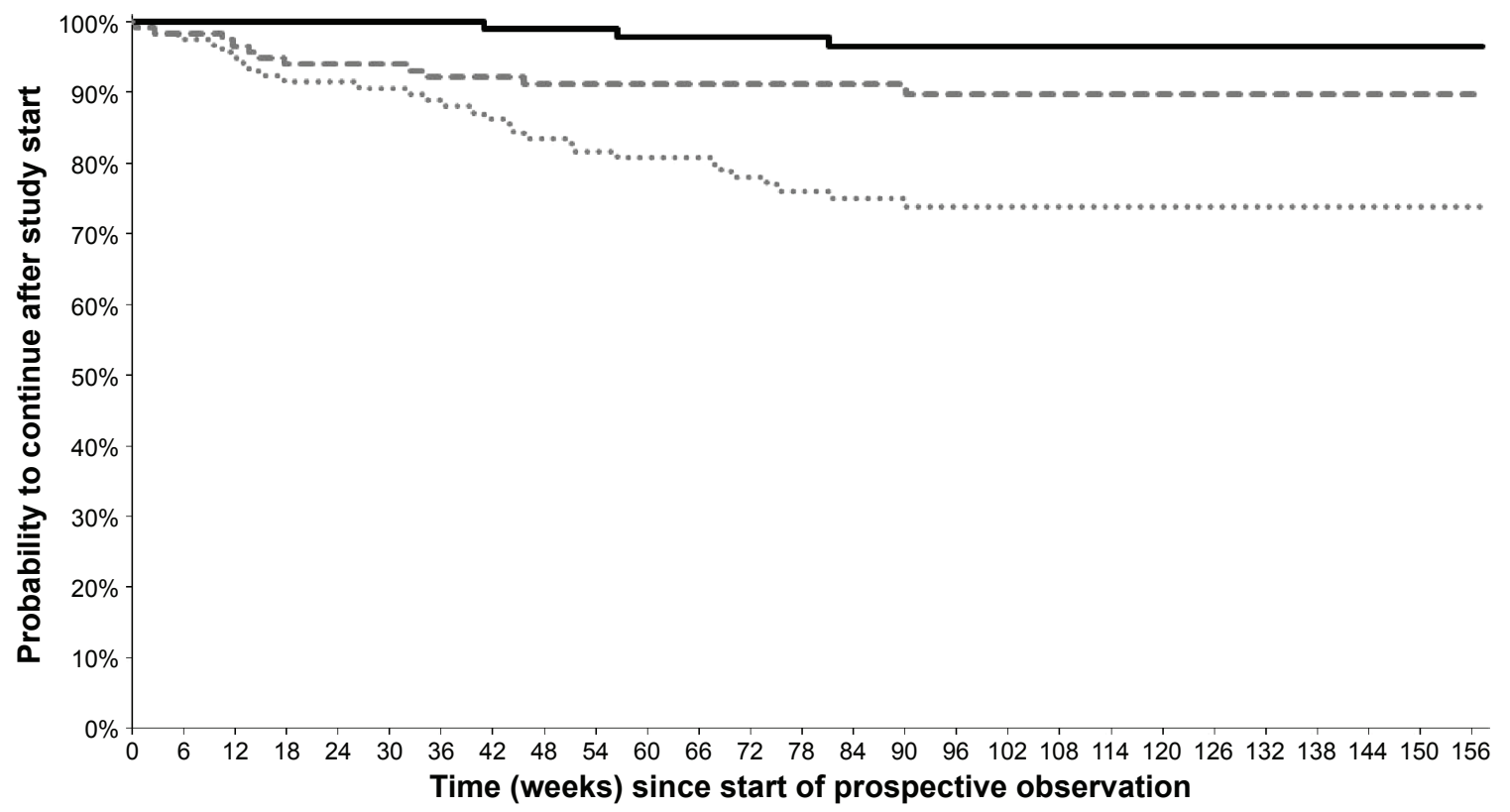

- - Discontinuation for AE, including death W Withdrawal for virologic failure ..... Medical or patient-related discontinuation

Figure 5 Kaplan-Meier curves from start of prospective observation showing study discontinuation by reason of interruption in Group 4 ( $n=1$ I 7) - ARV-naive patients. Abbreviations: $A E$, adverse event; $A R V$, antiretroviral. 
Table $6 \mathrm{CD}^{+}$cell count at study entry and at last study visit in the four groups of HIV-infected patients treated with DRV/r (LOCF analysis)

\begin{tabular}{|c|c|c|c|c|}
\hline CD4 ${ }^{+}$count, cells/ $\mu \mathrm{L}$ & Group I $(n=22 I)^{a}$ & Group $2(n=393)^{a}$ & Group $3(n=102)^{a}$ & Group $4(n=1 \mid 4)^{a}$ \\
\hline At study entry, median $\left(Q_{1}-Q_{3}\right)$ & $416(304,592)$ & $403(26 I, 589)$ & $322(203,484)$ & $116(34,302)$ \\
\hline At study entry, mean $\pm S D$ & $459 \pm 232$ & $449 \pm 267$ & $370 \pm 251$ & $185 \pm 183$ \\
\hline At last study visit, median $\left(\mathrm{Q}_{1}-\mathrm{Q}_{3}\right)$ & $488(328,655)$ & $473(32 I, 64 I)$ & $494(301,612)$ & $430(297,562)$ \\
\hline At last study visit, mean \pm SD & $512 \pm 262$ & $508 \pm 267$ & $507 \pm 280$ & $45 I \pm 218$ \\
\hline Change from study entry to last study visit, median $\left(Q_{1}-Q_{3}\right)$ & $+42(-39,+130)$ & $+49(-24,+144)$ & $+105(+24,+264)$ & $+254(+158,+385)$ \\
\hline Change from study entry to last study visit, mean $(95 \% \mathrm{Cl})$ & $+54(+32,+76)$ & $+59(+44,+74)$ & $+138(+100,+176)$ & $+266(+232,+300)$ \\
\hline
\end{tabular}

Notes: ${ }^{2}$ atients with both study entry and postbaseline CD4+ data available. Group I, patients who were part of the DRV/r Early Access Program (EAP); Group 2, patients already receiving DRV/r in routine clinical practice; Group 3, ARV-experienced DRV-naïve patients; Group 4, ARV-naïve patients.

Abbreviations: ARV, antiretroviral; $\mathrm{Cl}$, confidence interval; DRV/r, darunavir/ritonavir; HIV, human immunodeficiency virus; LOCF, last observation carried forward; $Q_{1}$, first quartile; $Q_{3}$, third quartile; SD, standard deviation.

In ARV-naïve subjects, over two-thirds (68.7\%) had a baseline VL $>100,000$ copies $/ \mathrm{mL}$ and $12.2 \%$ had a $\mathrm{VL}>1,000,000$ copies $/ \mathrm{mL}$. It is, therefore, very encouraging to report that the proportion of virological suppression in these previously untreated patients was $68.4 \%$ in the mITT analysis and $79.8 \%$ in the OT analysis. Interestingly, in ARV-naïve patients, $59.8 \%$ of subjects had a CD $4^{+}$cell count $<200$ cells $/ \mu \mathrm{L}$ and $47.9 \%$ had a count $<100$ cells $/ \mu \mathrm{L}$.

The results observed in the ARV-naïve DRV-naïve patients were similar to those achieved in the Phase III open-label
AntiRetroviral Therapy with TMC114 Examined In Naïve Subjects (ARTEMIS) trial. ${ }^{18}$ Similarly, in the 48-week oncedaily Darunavir in treatment-experienced patients (ODIN) trial comparing qd versus bid DRV/r in $590 \mathrm{ARV-experienced}$ HIV-infected patients, the proportions of patients achieving $\mathrm{VL}<50$ copies $/ \mathrm{mL}$ were $72.1 \%$ and $70.9 \%$, respectively $\left(P<0.001, \mathrm{qd} \mathrm{DRV} / \mathrm{r}\right.$ noninferior to bid DRV/r) ${ }^{14}$

With regard to safety, this study showed that DRV/rbased treatment was well tolerated. Only 26 patients (3\%) discontinued treatment due to AEs, 18 of which were deemed

Table 7 Median $\left(Q_{1}-Q_{3}\right)$ of serum biochemistry values during the study in patients with complete observations

\begin{tabular}{|c|c|c|c|c|c|}
\hline Laboratory parameter & Time (weeks) & Group I & Group 2 & Group 3 & Group 4 \\
\hline \multirow[t]{5}{*}{$\overline{A L T}, \mathrm{U} / \mathrm{L}$} & & $(n=150)$ & $(n=293)$ & $(n=67)$ & $(n=70)$ \\
\hline & $0^{\mathrm{a}}$ & $28(21,45)$ & $27(17,44)$ & $28(20,40)$ & $30(23,52)$ \\
\hline & $24 \pm 12$ & $27(19,43)$ & $28(18,44)$ & $23(15,4 I)$ & $19(15,28)$ \\
\hline & $48 \pm 12$ & $27(20,42)$ & $26(18,44)$ & $22(16,4 I)$ & $20(15,29)$ \\
\hline & $72 \pm 12$ & $28(20,4 \mathrm{I})$ & $28(|8,4|)$ & $23(16,42)$ & $19(15,26)$ \\
\hline \multirow[t]{5}{*}{ AST, U/L } & & $(n=148)$ & $(n=288)$ & $(n=66)$ & $(n=69)$ \\
\hline & $0^{a}$ & $27(20,36)$ & $25(19,39)$ & $26(20,4 I)$ & $29(23,42)$ \\
\hline & $24 \pm 12$ & $25(19,34)$ & $25(19,36)$ & $24(18,36)$ & $21(18,28)$ \\
\hline & $48 \pm 12$ & $26(19,35)$ & $25(19,35)$ & $23(19,37)$ & $21(18,25)$ \\
\hline & $72 \pm 12$ & $26(19,35)$ & $25(20,34)$ & $23(19,37)$ & $21(16,26)$ \\
\hline \multirow[t]{5}{*}{ Glucose, mg/dL } & & $(n=|4|)$ & $(n=289)$ & $(n=67)$ & $(n=68)$ \\
\hline & $0^{\mathrm{a}}$ & $90(83,98)$ & $89(83,98)$ & $84(78,95)$ & $87(83,96)$ \\
\hline & $24 \pm 12$ & $91(85,101)$ & $88(80,96)$ & $86(80,94)$ & $89(82,100)$ \\
\hline & $48 \pm 12$ & $90(84,101)$ & $88(82,96)$ & $85(79,96)$ & $89(83,98)$ \\
\hline & $72 \pm 12$ & $91(85,100)$ & $88(82,96)$ & $85(78,98)$ & $89(81,96)$ \\
\hline \multirow[t]{5}{*}{ Triglycerides, mg/dL } & & $(n=\mid 4 I)$ & $(n=274)$ & $(n=60)$ & $(n=59)$ \\
\hline & $0^{\mathrm{a}}$ & $18 \mid(121,238)$ & $154(1 \mid 2,232)$ & $148(94,201)$ & $120(88,148)$ \\
\hline & $24 \pm 12$ & $177(122,240)$ & $164(112,231)$ & $15 \mid(109,210)$ & $143(108,217)$ \\
\hline & $48 \pm 12$ & $157(\mid 18,226)$ & $152(107,240)$ & $153(97,218)$ & $152(108,244)$ \\
\hline & $72 \pm 12$ & $160(120,256)$ & $148(103,238)$ & $146(96,203)$ & $153(113,199)$ \\
\hline \multirow[t]{5}{*}{ Total cholesterol, mg/dL } & & $(n=129)$ & $(n=268)$ & $(n=56)$ & $(n=60)$ \\
\hline & $0^{\mathrm{a}}$ & $209(172,233)$ & $196(158,229)$ & I $74(148,204)$ & $149(129,183)$ \\
\hline & $24 \pm 12$ & $213(176,235)$ & $197(167,227)$ & $204(162,226)$ & $196(164,229)$ \\
\hline & $48 \pm 12$ & $197(177,230)$ & $197(164,227)$ & $198(162,226)$ & $193(17 \mid, 227)$ \\
\hline & $72 \pm 12$ & $211(174,243)$ & $199(167,234)$ & $196(160,232)$ & $189(160,217)$ \\
\hline
\end{tabular}

Notes: aBaseline within 3 months before study start. Group I, patients who were part of the DRV/r Early Access Program (EAP); Group 2, patients already receiving DRV/r in routine clinical practice; Group 3, ARV-experienced DRV-naïve patients; Group 4, ARV-naïve patients.

Abbreviations: ALT, alanine aminotransferase; ARV, antiretroviral; AST, aspartate aminotransferase; DRV/r, darunavir/ritonavir; $Q_{1}$, first quartile; $Q_{3}$, third quartile. 
possibly drug-related. This indicates that DRV/r is well tolerated in the routine clinical setting and has an overall tolerability profile similar to that observed in controlled clinical trials. ${ }^{14,18}$

These findings are consistent with those from controlled clinical studies, showing the long-term efficacy and tolerability of DRV/r. The current results in ARV-experienced DRV-naïve patients receiving DRV/r therapy are similar to those reported in the 48-week randomized controlled Phase III TITAN study of DRV/r 600/100 mg bid. ${ }^{15}$

The effectiveness, tolerability, and persistence data reported in this study are in agreement with those from other real-world studies. ${ }^{21-24}$ The body of evidence suggests that DRV-based therapy administered in routine care settings is associated with proportions of virological suppression similar to those seen in randomized controlled trials in most treatmentexperienced patients with HIV-infection ${ }^{14,18}$ This is true even in patients who have been treated for many years using several different ART regimens and who were failing current therapy due to lack of response or tolerability issues.

\section{Limitations}

The limitations of this study include the lack of a control arm and the different characteristics and origins of the study groups: two DRV-experienced groups (one from an EAP and one from routine clinical practice) and two DRV-naïve groups. However, these four groups reflect patients typically seen in daily clinical practice and may, therefore, help guide use of DRV/r in patients with HIV infection regardless of their treatment history, baseline VL, and $\mathrm{CD}^{+}$cell count. Another limitation to take into account is that Groups 1 and 2 (DRV-experienced subjects) excluded patients who eventually discontinued DRV/r due to virological failure or drug intolerance prior to study start (this was an exclusion criterion because of the difficulties associated with collecting clinical data retrospectively).

\section{Conclusion}

These data from a routine clinical setting showed that DRV/r was effective and well tolerated in all HIV-infected patient groups, when used in either initial or switch strategies. In all groups, DRV/r-based ART provided effective viral suppression with long-lasting durability and a low rate of withdrawals due to virological failure. The overall proportion of failures, also including discontinuation for any reason, and the tolerability profile of $\mathrm{DRV} / \mathrm{r}$ were favorable and similar to that reported in controlled clinical trials. ${ }^{11-15}$

\section{Acknowledgments}

The authors would like to thank all the study investigators (A Antinori, A d'Arminio Monforte, P Meraviglia,
G Rizzardini, A Lazzarin, P Nasta, C Mussini, T Quirino, R Cauda, G Sterrantino, A Chirianni, A Gori, M Borderi, G Di Perri, N Abrescia, I Mezzaroma, P Grossi, P Caramello, PE Manconi, F Di Sora, B Grisorio, G Parruti, P Bonfanti, G Angioni, L Minoli. S Rusconi, E Colella, G Penco, M Andreoni, L Titone, A Cattelan, L Cosco, L Sighinolfi, E Raise, and G Verucchi) and all the patients who consented to be part of the study. Medical writing assistance was provided by Mary Hines of Springer Healthcare Communications. This assistance was funded by Janssen-Cilag SpA (Italy).

\section{Disclosure}

AA has received honoraria for consultancy with Gilead Sciences, ViiV Healthcare, Merck Sharp \& Dohme, JanssenCilag, Abbvie, and Bristol-Myers Squibb and has also received research grants from Gilead Sciences, Bristol-Myers Squibb, Janssen-Cilag, and ViiV Healthcare. AdAM has been involved in advisory boards supported by Abbvie, Bristol-Myers Squibb, Gilead Sciences, Janssen-Cilag, and Merck Sharp \& Dohme. SR has received research funding from Pfizer and Janssen-Cilag and has been involved in advisory boards or educational courses supported by Abbvie, Boehringer Ingelheim, Bristol-Myers Squibb, Gilead Sciences, GlaxoSmithKline, now ViiV Healthcare, Merck Sharp \& Dohme, and JanssenCilag. NG has been advisor for Gilead Sciences, AbbVie, and Janssen-Cilag, received speakers' honoraria from Gilead Sciences, ViiV Healthcare, Bristol-Myers Squibb, Merck Sharp \& Dohme, Roche, AbbVie, Boehringer Ingelheim, and Janssen-Cilag, and support for travel to meetings from Gilead Sciences, Bristol-Myers Squibb, AbbVie, JanssenCilag, Merck Sharp \& Dohme, Roche, and ViiV Healthcare. $\mathrm{CM}$ has been involved in advisory boards or educational courses supported by Abbvie, Boehringer Ingelheim, BristolMyers Squibb, Gilead Sciences, GlaxoSmithKline, now ViiV Healthcare, Merck Sharp \& Dohme, and Janssen-Cilag. TB has received research funding and/or honoraria from Merck Sharp \& Dohme, Bristol-Myers Squibb, and Janssen-Cilag. GA has received honoraria for the statistical analysis of study data from Janssen-Cilag. DM and RT are employees of Janssen-Cilag SpA, Italy. PM, AC, and EC report no conflicts of interest in this work.

\section{References}

1. US Department of Health and Human Services [webpage on the Internet]. Guidelines for the Use of Antiretroviral Agents in HIV-1-Infected Adults and Adolescents: US Department of Health and Human Services (HHS) Panel on Antiretroviral Guidelines for Adults and Adolescents (a Working Group of the Office of AIDS Research Advisory Council); 2014 [updated May 1; cited October 7, 2014]. Available from: http:// aidsinfo.nih.gov/contentfiles/lvguidelines/adultandadolescentgl.pdf. Accessed March 1, 2016. 
2. Gazzard BG, Anderson J, Babiker A, et al; BHIVA Treatment Guidelines Writing Group. British HIV Association guidelines for the treatment of HIV-1-infected adults with antiretroviral therapy 2008. HIV Med. 2008;9:563-608.

3. Williams I, Churchill D, Anderson J, et al. British HIV Association guidelines for the treatment of HIV-1-positive adults with antiretroviral therapy 2012 (Updated November 2013. All changed text is cast in yellow highlight.). HIV Med. 2014;15(suppl 1):1-85.

4. Ministero della Salute [webpage on the Internet]. Linee Guida Italiane sull'utilizzo dei farmaci antiretrovirali e sulla gestione diagnosticoclinica delle persone con infezione da HIV 2013 [updated November; cited November 25, 2014]. Available from: http://www.salute.gov.it/ imgs/C_17_pubblicazioni_2074_allegato.pdf. Accessed March 1, 2016.

5. European AIDS Clinical Society [webpage on the Internet]. EACS Guidelines Version 7.02014 [updated October; cited 2014 November 25]. Available from: http://www.eacsociety.org/Portals/0/Guidelines_ Online_131014.pdf. Accessed March 1, 2016.

6. Janssen-Cilag International NV. Prezista (Darunavir). Summary of Product Characteristics 2016 [updated December 12, 2015]. Available from: http://www.ema.europa.eu/docs/en_GB/document_library/ EPAR_-_Product_Information/human/000707/WC500041756.pdf. Accessed March 18, 2016.

7. Phung BC, Yeni P. Darunavir: an effective protease inhibitor for HIVinfected patients. Expert Rev Anti Infect Ther. 2011;9:631-643.

8. McKeage K, Perry CM, Keam SJ. Darunavir: a review of its use in the management of HIV infection in adults. Drugs. 2009;69:477-503.

9. Deeks ED. Darunavir: a review of its use in the management of HIV-1 infection. Drugs. 2014;74:99-125.

10. Ortiz R, Dejesus E, Khanlou H, et al. Efficacy and safety of oncedaily darunavir/ritonavir versus lopinavir/ritonavir in treatment-naive HIV-1-infected patients at week 48. AIDS. 2008;22:1389-1397.

11. Mills AM, Nelson M, Jayaweera D, et al. Once-daily darunavir/ritonavir vs. lopinavir/ritonavir in treatment-naive, HIV-1-infected patients 96-week analysis. AIDS. 2009;23:1679-1688.

12. Pozniak A, Opravil M, Beatty G, Hill A, de Bethune MP, Lefebvre E. Effect of baseline viral susceptibility on response to darunavir/ ritonavir versus control protease inhibitors in treatment-experienced HIV type 1-infected patients: POWER 1 and 2. AIDS Res Hum Retroviruses. 2008;24:1275-1280.

13. Arasteh K, Yeni P, Pozniak A, et al. Efficacy and safety of darunavir/ ritonavir in treatment-experienced HIV type-1 patients in the POWER 1, 2 and 3 trials at week 96. Antivir Ther. 2009;14:859-864.

14. Cahn P, Fourie J, Grinsztejn B, et al. Week 48 analysis of once-daily vs. twice-daily darunavir/ritonavir in treatment-experienced HIV-1-infected patients. AIDS. 2011;25:929-939.

15. Madruga JV, Berger D, McMurchie M, et al; TITAN Study Group. Efficacy and safety of darunavir-ritonavir compared with that of lopinavir-ritonavir at 48 weeks in treatment-experienced, HIV-infected patients in TITAN: a randomised controlled phase III trial. Lancet. 2007;370:49-58.

16. Orkin C, DeJesus E, Khanlou H, et al. Final 192-week efficacy and safety of once-daily darunavir/ritonavir compared with lopinavir/ritonavir in HIV-1-infected treatment-naive patients in the ARTEMIS trial. HIV Med. 2013;14:49-59.

17. Banhegyi D, Katlama C, da Cunha CA, et al. Week 96 efficacy, virology and safety of darunavir/ $\mathrm{r}$ versus lopinavir/ $\mathrm{r}$ in treatment-experienced patients in TITAN. Curr HIV Res. 2012;10:171-181.
18. Lathouwers E, De Meyer S, Dierynck I, et al. Virological characterization of patients failing darunavir/ritonavir or lopinavir/ritonavir treatment in the ARTEMIS study: 96-week analysis. Antivir Ther. 2011; 16:99-108.

19. Podzamczer D, Imaz A, Perez I, et al; KIDAR Study Group. Abacavir/ lamivudine plus darunavir/ritonavir in routine clinical practice: a multicentre experience in antiretroviral therapy-naive and -experienced patients. J Antimicrob Chemother. 2014;69:2536-2540.

20. Menzaghi B, Ricci E, Carenzi L, et al. Safety and durability in a cohort of HIV-1 positive patients treated with once and twice daily darunavir-based therapy (SCOLTA Project). Biomed Pharmacother. 2013;67:293-298

21. Benea OE, Streinu-Cercel A, Dorobat C, et al. Efficacy and safety of darunavir $(\operatorname{Prezista}(\mathrm{R}))$ with low-dose ritonavir and other antiretroviral medications in subtype F HIV-1 infected, treatment-experienced subjects in Romania: a post-authorization, open-label, one-cohort, non-interventional, prospective study. Germs. 2014;4:59-69.

22. Gathe J. Experience with darunavir in HIV-infected adults enrolled in a US expanded access program: results from a single center. Curr Med Res Opin. 2008;24:769-773.

23. Ribeiro KM, Biscione FM, Westin MR, Machado DP, Greco DB, Tupinambas U. Virologic and immunologic effectiveness of darunavirbased salvage therapy in HIV-1-infected adults in a Brazilian clinical practice setting: results of a multicenter and retrospective cohort study. Braz J Infect Dis. 2014;18:1-7.

24. Willig JH, Aban I, Nevin CR, et al. Darunavir outcomes study: comparative effectiveness of virologic suppression, regimen durability, and discontinuation reasons for three-class experienced patients at 48 weeks. AIDS Res Hum Retroviruses. 2010;26:1279-1285.

25. Kim H, Perelson AS. Viral and latent reservoir persistence in HIV-1infected patients on therapy. PLoS Comput Biol. 2006;2:e135.

26. Molina JM, Cohen C, Katlama C, et al; TMC114-C208 Study Group; TMC114-C215 Study Group. Safety and efficacy of darunavir (TMC114) with low-dose ritonavir in treatment-experienced patients: 24-week results of POWER 3. J Acquir Immune Defic Syndr. 2007; 46:24-31.

27. De Meyer SM, Spinosa-Guzman S, Vangeneugden TJ, de Bethune MP, Miralles GD. Efficacy of once-daily darunavir/ritonavir 800/100 mg in HIV-infected, treatment-experienced patients with no baseline resistance-associated mutations to darunavir. $J$ Acquir Immune Defic Syndr. 2008;49:179-182.

28. Clotet B, Bellos N, Molina JM, et al; POWER 1 and 2 Study Groups. Efficacy and safety of darunavir-ritonavir at week 48 in treatmentexperienced patients with HIV-1 infection in POWER 1 and 2: a pooled subgroup analysis of data from two randomised trials. Lancet. 2007;369:1169-1178.

29. Berhan A, Berhan Y. Virologic response to tipranavir-ritonavir or darunavir-ritonavir based regimens in antiretroviral therapy experienced HIV-1 patients: a meta-analysis and meta-regression of randomized controlled clinical trials. PLoS One. 2013;8:e60814.

30. Raffi F, Babiker AG, Richert L, et al; NEAT001/ANRS143 Study Group. Ritonavir-boosted darunavir combined with raltegravir or tenofovir-emtricitabine in antiretroviral-naive adults infected with HIV-1: 96 week results from the NEAT001/ANRS143 randomised non-inferiority trial. Lancet. 2014;384:1942-1951.

\section{Publish your work in this journal}

Drug Design, Development and Therapy is an international, peerreviewed open-access journal that spans the spectrum of drug design and development through to clinical applications. Clinical outcomes, patient safety, and programs for the development and effective, safe, and sustained use of medicines are a feature of the journal, which

\section{Dovepress}

has also been accepted for indexing on PubMed Central. The manuscript management system is completely online and includes a very quick and fair peer-review system, which is all easy to use. Visit http://www.dovepress.com/testimonials.php to read real quotes from published authors. 